\title{
LA NOCIÓN DE PERSONA ENTRE LOS MAYAS: UNA VISIÓN SEMÁNTICA
}

Gabriel Luis Bourdin

IIA UNAM

\section{RESUMEN}

El presente trabajo está dedicado a las representaciones culturales de la persona entre los mayas yucatecos. Se enfoca la noción de persona partiendo de las categorías conceptuales contenidas en el vocabulario. Se intenta dar una visión semántica de la categoría de persona, atendiendo al significado de las palabras empleadas para identificar los diversos componentes del ser humano individual. Se identifican algunos de los conceptos fundamentales referidos a los diversos componentes que integran el ser humano en la concepción de esta cultura. Entre los mayas peninsulares modernos, el individuo humano se concibe como una unidad de wiinkilil "cuerpo", pixan "alma" y ool "ánimo"; esta concepción difiere en alguna medida de la que se infiere a partir de los testimonios en maya colonial, y también de las de otros pueblos hablantes de lenguas mayances, entre otras cosas por la ausencia entre los mayas peninsulares de la idea de un "doble animal" asociado de modo íntimo con la vida del individuo.

Palabras clave: persona, maya yucateco, semántica léxica. 


\begin{abstract}
The present paper studies cultural representations of person among Yucatec Mayas. The study is focussed on the notion of person starting from the conceptual characteristics contained in the vocabulary. The paper attempts to give a semantic point of view of the category of person, considering the meaning of the words used to identify the different components of the human being taken as an individual. Some of the essential concepts that refer to the diverse components of the individual human being are identified here. Among the modern Peninsular Mayas, the human being is conceived as a unit of wíinkilil -body-, pixán-soul-, and óol-spirit. This conception somewhat differs from the idea that has been transmitted by Colonial Maya testimonies and by other people speaking Mayan languages. Among other things, this happens because of the absence, among Peninsular Mayas, of an “animal companion”, idea which is closely related to the individual's life.
\end{abstract}

Key words: person, mayan language, semantic terms 


\section{UN ENFOQUE SEMÁNTICO INTERCULTURAL DE LA CATEGORÍA DE PERSONA}

La semántica es la disciplina que analiza el significado lingüístico; la semántica intercultural se ocupa del significado en las diferentes culturas (Martín y Pérez 1998). En tiempos recientes antropólogos, lingüistas y semantistas, se han dado a la tarea de describir y analizar los dominios léxico-semánticos referidos a la expresión de la corporeidad, de las emociones $\mathrm{y}$, de modo directo o indirecto, de las nociones de persona relacionadas con diferentes lenguas. Las lenguas naturales — junto al discurso etnopsicológico (Kitayama y Marcus 1991, 1994) que las mismas posibilitan y condicionan — incluyen siempre una representación de las facultades anímicas, morales y emocionales del ser humano como realidades contenidas en el interior del cuerpo, de modo indistinto o ubicadas en un órgano específico.

Esta etnoteoría, relativa a la condición y composición de la persona, es conocida también como "teoría visceral" de las emociones y los estados de ánimo (Heelas 1996). Algunos autores sugieren que la misma está difundida a escala universal, en todas o casi todas las lenguas o culturas (Enfield y Wierzbicka 2002). El análisis semántico del vocabulario relacionado con los dominios del cuerpo, las facultades y entidades anímicas, las emociones y la noción de persona, proporciona un tipo de información cultural que es inaccesible por otros medios. Las nociones culturales acerca de cómo está formada una persona no pueden derivarse de la observación directa; las emociones de otros seres humanos pueden inferirse a partir de sus gestos y expresiones faciales, pero no conoceremos realmente sus pensamientos, sentimientos y deseos hasta que no los hayan formulado verbalmente, 
aunque siempre sea posible fingir o mentir. De modo que la lengua y el discurso son los principales medios para el conocimiento de las nociones etnopsicológicas propias de un individuo o de un grupo humano.

Como es evidente, los sistemas culturales de clasificación se encuentran asociados con términos y otros elementos léxicos y morfosintácticos de las lenguas con las que dichos sistemas de categorización están relacionados. Aunque existen ciertas tendencias universales, las diferentes lenguas y culturas categorizan y denominan el dominio semántico del cuerpo y de la persona de maneras diversas. Al adoptar una perspectiva intercultural, la semántica lingüística de orientación antropológica se constituye en el medio adecuado para captar esa diversidad de matices y componentes significativos que hacen a la singular categorización del mundo propia de cada cultura particular.

Al escoger, simultáneamente, una perspectiva de la semántica basada en primitivos $y$ universales (Goddard y Wierzbicka 1994) pretendemos poner de manifiesto el hecho de que el significado de la experiencia propia de los miembros de una cultura y de los hablantes de una lengua es, en alguna medida, traducible a términos de conceptos y nociones universales. Así, por ejemplo, al analizar el vocabulario del maya yucateco referido a los dominios en cuestión encontramos un elemento léxico, el término ool, glosado normalmente como "ánimo", "voluntad” y "corazón formal”. Esta noción referida al interior más íntimo de la persona humana presenta numerosas conexiones semánticas. El término ool es polisémico de un modo notable y no un equivalente exacto en lenguas como 
el español o el inglés, ya que por ejemplo equivale a lo que llamaríamos el "alma" y de modo indistinto el "espíritu", o también la "mente" y los "sentimientos", etcétera. Pero además de ello, es el centro medular del individuo vinculado al germen del crecimiento vegetal, es el "cogollo tierno" de plantas, árboles y flores. Asimismo posee connotaciones cosmológicas que vinculan el "núcleo" de la persona con el centro del mundo. Por todas estas razones, ool puede considerarse asociado con un concepto cultural idiosincrático, propio y singular de la cultura y de la lengua que lo han concebido. Desde otra perspectiva, diferente pero complementaria con la anterior, el análisis semántico de ool en términos de primitivos y universales léxico-semánticos nos sugiere que se trata de una noción compleja cuya descripción involucra básicamente los primitivos Sentir, Querer, Dentro, Moverse y Vivir (Wierzbicka 1999). La semántica intercultural es capaz de describir los significados de las diversas lenguas en términos de su relación con los aspectos específicos de cada cultura particular, y también con referencia a criterios universalistas de comunicación intercultural.

\section{ACERCA DE LA NOCIÓN DE PERSONA COMO CATEGORÍA UNIVERSAL}

Una de las últimas conferencias dictadas por Marcel Mauss (1938) estuvo dedicada a la categoría universal de persona y al proceso de su sociogénesis. Mauss asociaba allí a la persona con el yo —en francés moi-. La relación entre estas dos nociones, y singularmente el hecho de que la primera persona del singular en cuestión pueda expresarse en francés con el pronombre personal "moi”, que funciona en ciertos casos con el papel de un objeto gramatical, en lugar de emplear je, que es también un pronombre personal de 
primera persona, pero que sólo puede asumir función de sujeto, ilustra el hecho de que el estudio de la categoría de persona puede beneficiarse con el aporte de un enfoque lingüístico. En nuestra opinión, un abordaje de este tipo debería tomar como su objeto de estudio el vínculo existente entre, por una parte, los procesos de construcción cultural de subjetividades o personas, y por otra las estructuras semánticas, gramaticales, discursivas y de otros tipos, propias de la lengua en cuestión.

Kant caracterizaba a la persona de acuerdo con los atributos de responsabilidad y conciencia: "una persona es un sujeto responsable de sus acciones"; y "una persona es algo que es conciente en diferentes momentos de la identidad numérica de su yo" (Eccles 2000: 278). Esta es una definición ajustada, del modo más preciso, a la mentalidad europea moderna. Es plausible la suposición de que tal caracterización kantiana de la persona dista mucho de ser universal. Las formas en que las diversas culturas realizan las condiciones empíricas de la categoría universal de persona son muy variadas. A continuación presentamos algunos ejemplos referidos al vocabulario maya yucateco, particularmente centrados en el dominio de las emociones y en los atributos anímicos de la persona. También presentaremos algunas comparaciones con términos análogos en otras lenguas mayas.

Mauss dejó de lado el tratamiento lingüístico de la noción de persona al decir: "sobre este vasto campo de las lenguas, soy un científico mediocre. Mi investigación será completamente un estudio acerca del derecho y la moral" (1938: 264). Por nuestra parte, 
intentaremos aquí una exploración de la noción de persona enfocándola a partir del sistema de convenciones y signos lingüísticos; estos, de modo necesario y junto con las normas del derecho y de la moral, intervienen en la constitución de la categoría cultural en cuestión. En esta misma conferencia, Mauss pasa revista a las representaciones culturales de la persona en diversos pueblos del mundo: los habitantes de la costa noroccidental de Norteamérica, los pueblos del suroeste de Estados Unidos, los arunta del desierto australiano. En todos estos casos la personalidad individual se presenta como una totalidad conformada por diversos aspectos o componentes. Dichos aspectos son simbolizados en algunos casos como partes del cuerpo del tótem o animal emblemático del clan, o como rasgos de esta personalidad mítica. De acuerdo con la información proporcionada por el vocabulario maya, que hemos analizado, no hay en este sistema de conceptos referencias al hecho de que las personas individuales comunes incluyan un componente anímico asociado con partes de un personaje totémico, ni otras asociaciones con el mundo animal o de tipo totémico. Esto a excepción de la noción de uaay, el familiar, atributo que parece haber sido exclusivo de los llamados brujos y hechiceros.

Otra forma, muy difundida a través de las culturas, de representar los diversos componentes o "personalidades" que confluyen en la constitución de un individuo o persona, es la asignación de varios nombres propios. Tales nombres son asignados al individuo en diversos momentos y circunstancias a lo largo de su vida, e incluso más allá de ella se asigna un nombre a su alma o al elemento de tipo espiritual que, según se piensa, sobrevive a la muerte física. Mauss afirma que los nombres son elementos centrales en la 
sociogénesis de la persona y se consideran parte esencial de la personalidad. Están asociados íntimamente con las prácticas y creencias de tipo totémico que Mauss describe.

En dichos contextos los diferentes nombres y títulos son otorgados a los individuos a lo largo de su vida y se transmiten a través de las generaciones junto con las máscaras, imágenes y otros objetos rituales que forman el patrimonio de un determinado linaje o grupo de parientes. Este hecho refuerza la idea de que las palabras y el lenguaje no son simples nombres puestos a las cosas sino que, por el contrario, son parte constitutiva de los individuos humanos o personas; el habla tiene una influencia o eficacia especial sobre los hablantes.

\section{COMPONENTES DE LA PERSONA EN MAYA YUCATECO}

Vale la pena aclarar que si bien el título del presente artículo hace alusión a la noción de persona entre los mayas del modo más amplio, en esta oportunidad nos referiremos solamente a las nociones mayas yucatecas, a las que se añade un ejemplo cuyo propósito es contrastivo, el de los tsotsiles, otro grupo de la familia maya. De todas formas la elección del término étnico "maya" nos parece acertada en cuanto pertenece a la así autodenominada maaya t'an o lengua maya. Existe, ciertamente, la posibilidad de estudiar comparativamente las nociones de persona y muchas otras del dominio etnopsicológico, como los términos referidos a emociones, estados de ánimo, caracteres personales, relaciones interpersonales, etcétera, en las demás lenguas de esta familia, de México y Centroamérica. Un propósito de tal alcance supera las posibilidades de un investigador 
aislado, requiriendo la colaboración de varios profesionales versados en lenguas mayances y en etnografía de campo. El tratamiento de las nociones de persona en varias lenguas mayas excede, naturalmente, las posibilidades del presente artículo.

En cuanto a los componentes de la persona a través del vocabulario maya, una investigación acerca del yucateco colonial, basada en el Calepino de Motul (Arzápalo 1995), ofrece como resultado el siguiente conjunto de términos y conceptos (Bourdin 2007).

$\begin{array}{ll}\text { uinic } & \text { hombre } \\ \text { cucutil } & \text { cuerpo } \\ \text { ool } & \text { corazón formal, ánimo } \\ \text { puczikal } & \text { corazón material } \\ \text { pixan } & \text { alma } \\ \text { cux } & \text { vida } \\ \text { ik } & \text { espíritu } \\ \text { kinam } & \text { energía } \\ \text { than } & \text { palabra } \\ \text { tucul } & \text { pensamiento } \\ \text { uaay } & \text { familiar }\end{array}$

Este listado es hipotético, y seguramente incompleto; sin embargo incluye lo que al parecer son los conceptos fundamentales de la concepción maya del ser humano o uinic. Nos 
ocuparemos en esta ocasión de los términos ool, referido al ánimo, y pixan, que designa el alma.

\section{EL “CORAZÓN FORMAL” COMO “MEOLLO” DE LA PERSONA}

El término ool es glosado en las fuentes coloniales como "corazón formal", por contraste con puczikal, el "corazón material”. La pareja de contraste formal vs. material expresa imperfectamente las nociones presentes en el pensamiento maya tradicional. En primer lugar, forma y materia son nociones pertenecientes a la concepción escolástica tomista, de los evangelizadores del siglo XVI, donde el cuerpo es sustancia y el alma es forma; es en esta acepción del alma igual a forma que debe entenderse la glosa de ool como corazón formal. El término ool es polisémico, siendo un elemento muy productivo dentro de lo que podemos llamar el vocabulario etnopsicológico del maya yucateco. Podemos suponer incluso que se trata de un término clave dentro de esta cultura (cf. Wierzbicka 1997). El Calepino de Motul ofrece no menos de siete entradas distintas referidas a diferentes usos de ool, junto a una enorme cantidad de derivados y formas compuestas con el mismo. Así por ejemplo, gran cantidad de las expresiones con significado de tipo emocional en esta lengua está formada en composición con ool. En los siguientes ejemplos vemos diferentes usos de este término:

1) ool corazón formal y no el material 


\title{
cii-oob y-ool in mehen-oob \\ 'gustoso’-3P ABS 3P-‘ánimo’ 1S POS ‘hijo’-P \\ alegres y contentos están mis hijos
}

2) ool voluntad y gana

\author{
yan u-ool tii benel \\ 'tener' 1S- 'ánimo’ PREP 'ir' \\ tengo gana y voluntad de irme
}

En 1 observamos el uso de ool con el sentido figurativo de una sede o locación de la experiencia emocional, en este caso se hace referencia a un sentimiento que traducimos como "alegría". En otros contextos, como en 2, el término se asocia con el significado "voluntad" y con una serie de conceptos relacionados con querer, intención o intento. También encontramos una entrada correspondiente al dominio botánico, que reviste gran interés para nuestro tema:

ool tallo o cogollo tierno, así de yerbas como de árboles y otras plantas

y-ool coles el cogollo o meollo de la col

y-ool haaz el cogollo o meollo de la lechuga

La alusión a ool como una parte o componente medular de los vegetales está relacionada con el atributo de centralidad contenido en este concepto. Tomado como componente 
anímico de la persona, ool es la médula de la persona o individuo. Puede observarse que la analogía está referida no solo a la noción de una región o espacio geométrico, sino también a la idea de un núcleo a partir del cual se irradia un cierto crecimiento o movimiento vital de orientación centrífuga y ascendente. Por otra parte, estas nociones parecen relacionarse con las concepciones antropológicas y cosmológicas tradicionales de la cultura maya, referidas al corazón como un punto central a partir del cual se irradia la vida y se organizan el espacio y el tiempo. De manera que ool, el corazón formal, puede interpretarse como la representación de la voluntad o deseo individual, del sentimiento o emoción en su aspecto más interno, y en cierto modo como condición o identidad social de una persona, como lo sugieren los siguientes ejemplos:

3) oolili la condición que uno tiene

u-oolili esta es mi condición

a u-oolili $\quad$ esta es tu condición

y-oolili Juan la condición de Juan

naan y-ool Juan t-en

'conocida' 3S- ‘condición' Juan PREP-1S ABS

conozco y sé la condición de Juan

Tanto en el aspecto formal como en el material el corazón es concebido como sede o centro principal de la vida anímica; voluntad, deseo, sentimientos, afectos, estados emotivos, pasiones y ciertas facultades asociadas con el entendimiento y la imaginación se relacionan 
con este centro privilegiado del microcosmos personal. En tal sentido, el pensamiento maya no se aparta de muchas otras concepciones culturales que atribuyen idénticas funciones al corazón. Si comparamos dichas concepciones con las nociones occidentales modernas del psiquismo y de la persona, resalta el contraste entre el corazón y la cabeza o el cerebro, ya que en la concepción moderna, el centro de la vida psíquica es inequívocamente el cerebro, y secundaria o metafóricamente aludimos al corazón como la sede de los sentimientos y las pasiones.

El término ool se emplea en varias lenguas mayas para referirse al corazón en un sentido material y psicológico. De acuerdo con Schumann:

\footnotetext{
En todas las lenguas mayas el punto de referencia para las expresiones que indican sentimiento, simpatía o estado de ánimo, es el interior del cuerpo o, si no, es lo que se puede traducir por el corazón; se indica que es allí donde se siente o que participa de manera activa en estas construcciones. Hay que tomar en cuenta que por corazón no se debe entender solamente el órgano, sino también el medio que lo rodea, como la boca del estómago. Cuando no se parte de los dos puntos anteriores, se toma como punto de referencia el alma, que de cualquier forma la sitúan en uno de los dos puntos antes mencionados. En el maya mopán se toma como referencia el alma, que en estas lenguas se señala mediante un sustantivo que va generalmente poseído /ool/, lo mismo sucede en el maya yucateco y en el maya itzá (1997: 194).
}

Los médicos tradicionales mayas de nuestros días diferencian dos formas del alma: el pixan y el ool (García, Sierra y Balám 1996). Esta imagen de la persona conformada por dos almas parece coincidir con nuestros datos del maya colonial. En la concepción de estos 
médicos tradicionales ool involucra la idea de una fuerza vital inherente a la persona humana, capaz de mantener la salud o de alterarse, produciendo enfermedades. Por ejemplo, una persona con "exceso de calor" —embarazada, menstruante, enojada, etcétera- puede enfermar a un niño pequeño y desnutrido, porque ese niño tiene un ool demasiado débil. Para comprender el sistema de ideas y la práctica de la medicina tradicional maya es necesario identificar los conceptos anímicos en los términos de la lengua y de la cultura en cuestión.

Para los h-menoob actuales ool es una fuerza vital. La noción es asimilable al tonalli náhuatl, es decir, una entidad anímica que suele traducirse como "soplo o aire de la vida". Se piensa que el ool se adquiere a través de la respiración, que llega a los pulmones y desde allí se dirige al corazón, donde tiene su asiento y desde donde se distribuye a todo el cuerpo teniendo como vehículo la sangre. Se lo representa como una energía caliente relacionada con enfermedades del tipo denominado síndrome cultural, como el mal de ojo y el susto. Según se piensa dichas enfermedades están causadas por la influencia de personas con ool fuerte sobre otras personas de ool débil. En este sentido se asemeja a la noción de kinam de los mayas antiguos y de otros pueblos de la familia maya. El ool también puede salir del cuerpo en los sueños y enfermar a otras personas. Se cree que cuando alguien muere su ool hace abandono del cuerpo y se dispersa en el aire como un vapor caliente. En este sentido se asemeja también a la noción del ihiyotl de la concepción nahua antigua (López Austin 1996), aunque en este caso, la entidad anímica se concebía como localizada en el hígado, en vez de estar asociada con el corazón. 
En mi opinión, esta noción maya moderna de ool, como entidad anímica de naturaleza aérea, caliente y proyectable hacia el exterior, es diferente de la que manifiestan las fuentes mayas coloniales, pero distinta también de las ideas expresadas en la distinción occidental de cuerpo y alma.

\title{
EL ALMA COMO "ENVOLTURA"
}

Otro término referido a un componente esencial de la persona es pixan, glosado convencionalmente como "alma":

4) pixan alma que da vida al cuerpo del hombre

\author{
pixan in cah \\ 'alma' 1S POS 'tener' \\ tengo alma
}

En apariencia pixan, alma, puede interpretarse equivalente a ool, ánimo. Sin embargo, podemos reconocer significativos contrastes entre uno y otro término. El término pixan designa literalmente "envoltura" o "cobertura". Diversos ejemplos del uso de la raíz pix-, cubrir o envolver, sus derivados y compuestos, abonan la idea de que pixan corresponde a la noción de una cobertura o envoltura de la persona. 
El término se relaciona con la vestimenta y es precisamente el nombre de una prenda que cubre la cabeza y el cuello que forma parte de la indumentaria ceremonial maya. En tanto representa una vestidura, el pixan es susceptible de ser "manchado". Se lo asocia con la noción de culpa y puede ser mancillado por los pecados cometidos. Como se aprecia en el siguiente ejemplo:

5) xihul mancha, mácula, mancilla y tacha o nota en persona y culpa así

$$
\begin{gathered}
\text { yaab u xihul in nok, u xihul in pixan } \\
\text { 'mucho' 3S POS 'mancha' 1S POS 'ropa', 3S POS 'mancha' 1S POS 'alma' } \\
\text { muchas manchas tiene mi ropa, y mucha mancilla mi alma }
\end{gathered}
$$

Numerosos ejemplos de uso de pixan en el discurso maya colonial manifiestan la asociación de este término con la noción del alma propia del catolicismo maya. Los datos etnográficos coinciden en este punto. Se piensa que pixan es el ánima de los difuntos que se separa del cuerpo con la muerte. En este sentido parece coincidir con la noción cristiana del alma inmortal, cuya existencia es trascendente a la vida corporal. La celebración del día de Muertos entre los mayas yucatecos actuales es conocida como hanal pixan, literalmente "la comida de las ánimas”. 


\section{DIVERSAS REPRESENTACIONES ESQUEMÁTICAS DE LA NOCIÓN DE PERSONA}

Para resumir los elementos esbozados hasta aquí podemos usar un esquema de tipo icónico que obedece a la distinción establecida entre las nociones de ool como meollo vs. pixan como envoltura.

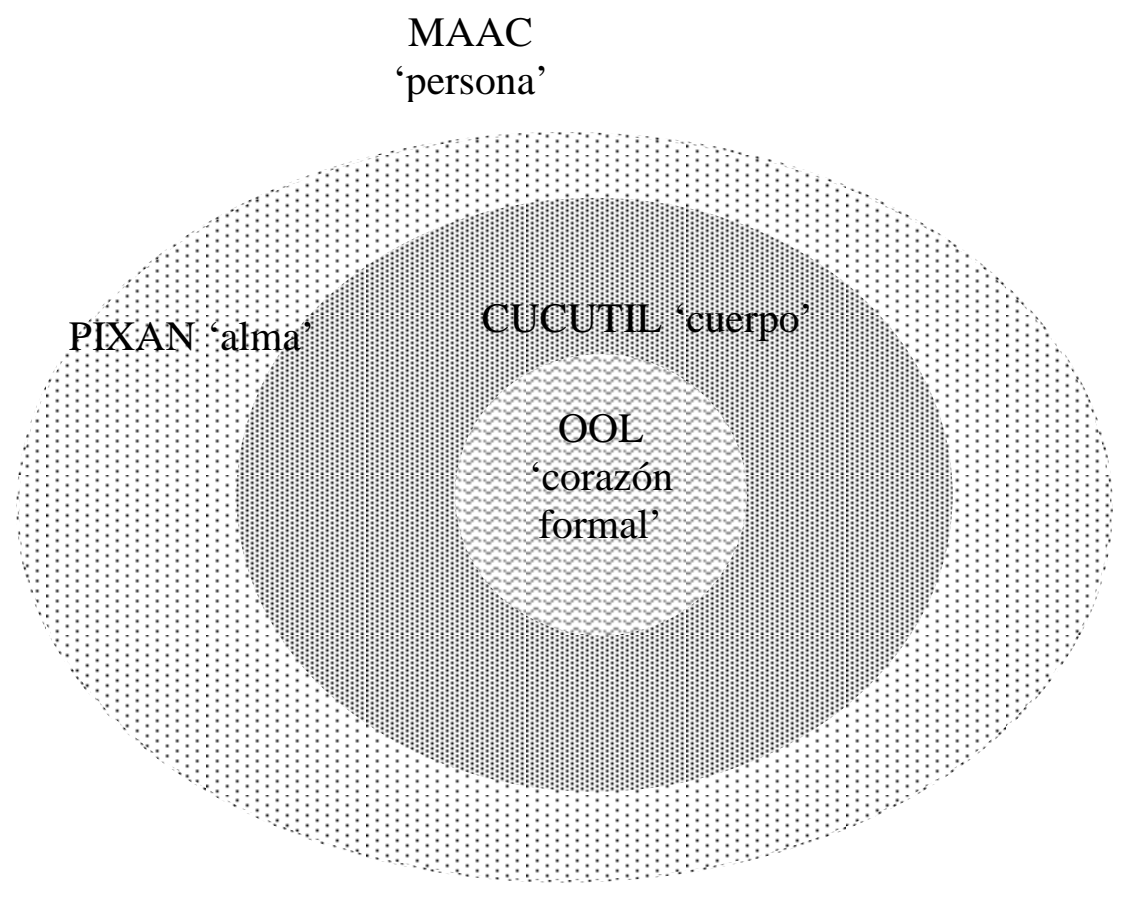

Figura 1. Esquema de la noción de persona en yucateco colonial.

Por su parte, Holland (1989: 101) ofrece una representación gráfica de lo que denomina "los componentes de la naturaleza humana" en la concepción de los tsotsiles. De acuerdo con este autor, en la concepción maya tsotsil la naturaleza humana está compuesta por dos elementos materiales, el hueso y la carne, y un componente inmaterial o espiritual. Ambos se interrelacionan dinámicamente en el seno del individuo o persona. Los factores que 
incumben al ch'ulel o espíritu afectan también a la carne y al hueso, así por ejemplo las enfermedades que afectan al elemento inmaterial aquejan también el aspecto material de la persona y viceversa. La noción de ch'ulel o espíritu hace alusión a la fuerza vital de la naturaleza, que da vida y que es indestructible.

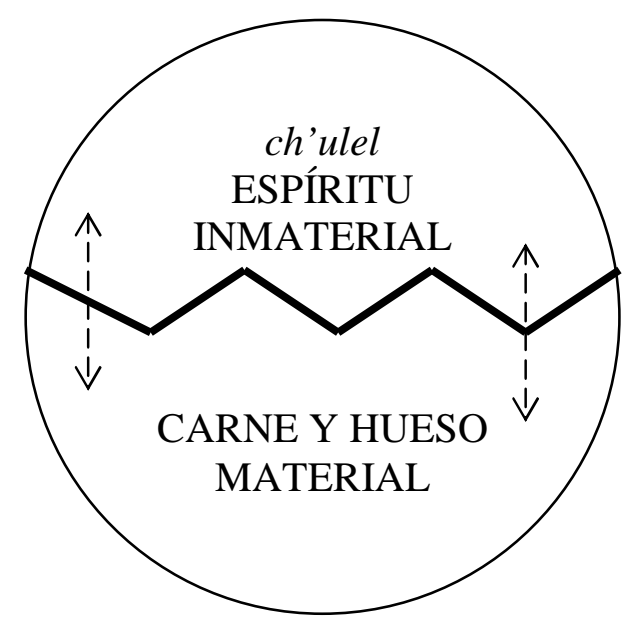

Figura 2. Interrelaciones de los componentes de la naturaleza humana.

Se piensa que el ch'ulel se manifiesta en todos los reinos vivientes: humanos, animales y vegetales. En este aspecto, la noción de ch'ulel se diferencia de la de ool, el corazón formal del maya yucateco, pues este último es un componente - al parecer- exclusivo del ser humano; no existen menciones al corazón formal como atributo de animales o plantas. Tampoco hace excepción a lo anterior el hecho de que se use el mismo término ool para aludir al cogollo o meollo tierno de árboles y plantas. Por otra parte, el ch'ulel es considerado indestructible, como lo es aparentemente el pixan o alma inmortal de los yucatecos, pero a diferencia de ool, al que, al menos en la actualidad, suele describirse con 
la figura de un "gas caliente" que, al morir una persona, abandona el cuerpo disolviéndose en el aire.

Según Holland los tsotsiles piensan que los componentes materiales, la carne y el hueso, son finitos y mortales; y el ch'ulel o espíritu es infinito e inmortal. El espíritu existe antes del nacimiento y después de la muerte de la persona, de modo que puede subsistir con independencia de la vida corporal. Posee dos manifestaciones o aspectos que no pueden disociarse durante la vida de una persona: uno es el ch'ulel, el espíritu individual, el componente inmaterial de la persona; el otro aspecto es una proyección de las características del espíritu individual sobre un miembro individual de una especie animal, el “compañero animal", llamado wayjel en tsotsil. Comparten un mismo espíritu y un destino corporal común, ya que aquello que afecta a la persona afecta también a su doble animal, y viceversa. El animal compañero, dice Holland: "es un tótem personal que representa y simboliza el individuo al que corresponde". Estas ideas son muy bien conocidas, de manera que nos limitaremos a dar las indicaciones más esquemáticas posibles con el fin de llegar directamente al punto que deseamos señalar. Para explicar la relación, entre ch'ulel y wayjel, que es por cierto algo confusa, Holland propone un segundo esquema que describe las relaciones entre la persona y el animal compañero (1989: 102). 


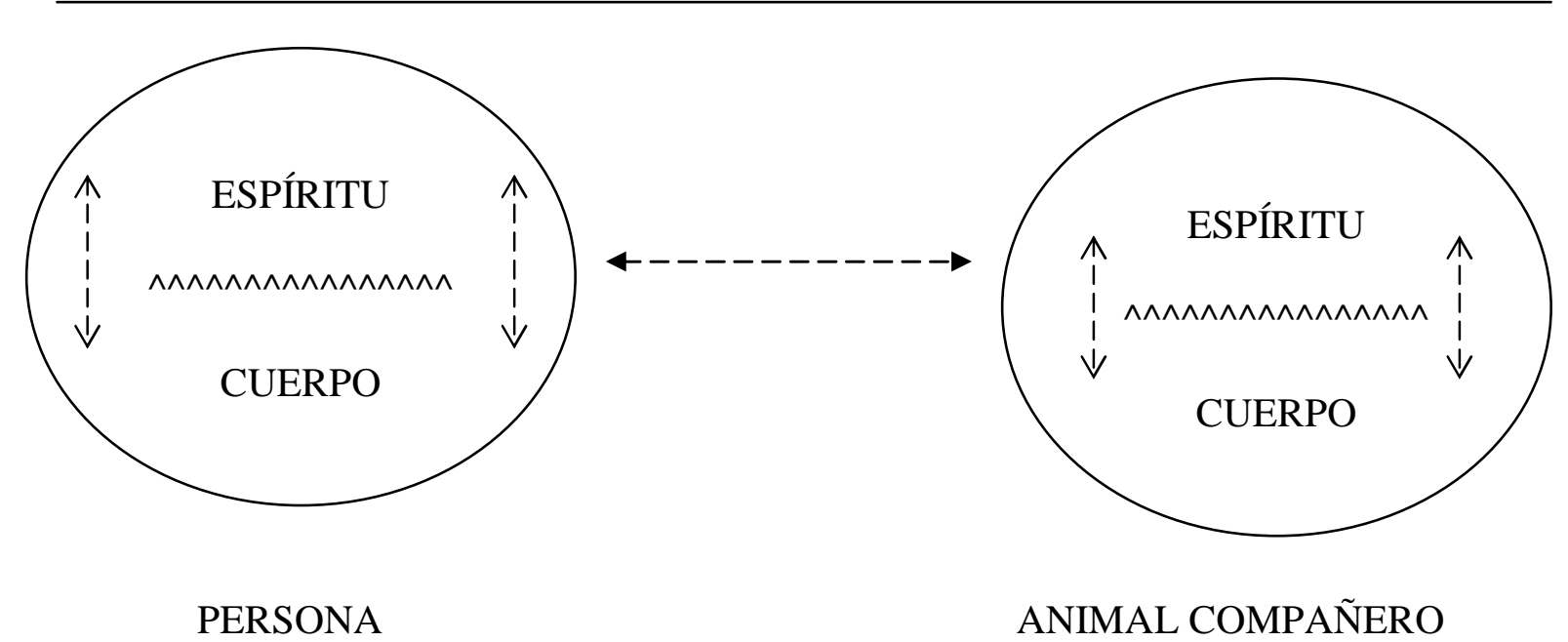

Figura 3. Relaciones entre la persona y su animal compañero.

En esta concepción, la persona involucra un elemento extracorpóreo. También pixan, la envoltura de la persona de los mayas yucatecos, es extracorpóreo, pero el animal compañero de los tsotsiles es de un tipo diferente, ya que wayjel habita, según se piensa, en las montañas. La noción de "doble animal" describe bien la situación, dado que se trata de una suerte de desdoblamiento del espíritu y de los cuerpos, que se establece a partir del nacimiento: cuando nace un niño en el pueblo simultáneamente nace un animal en la montaña. El destino y la naturaleza de ambos es una identidad desdoblada y sincronizada desde su origen, cuyas manifestaciones están focalizadas en el ámbito humano, por ejemplo la correspondencia entre un alto estatus social y un animal compañero poderoso, o las enfermedades que se consideran causadas por la captura o muerte del compañero animal. 
Las sucesivas etapas del ciclo vital y los progresos en el estatus social de las personas se reflejan también, según se piensa, en la posibilidad de cambiar el compañero animal por uno de mayor rango, por ejemplo el coyote por el jaguar, etcétera.

Podemos preguntarnos si estas nociones que hemos englobado como referidas a un doble animal no representan un verdadero contraste con respecto a la idea kantiana, que mencionábamos al comienzo, de la persona como "algo que es conciente de la identidad numérica de su yo". En lo tsotsil, de manera patente, la persona es una entidad desdoblada espacialmente, el radio de alcance de este desdoblamiento comprende los diversos medios o ámbitos humanos y naturales - lugar donde se habita vs. montañas, etcétera- que modelan y otorgan contenido al universo cultural de este pueblo.

Vale la pena apuntar, referido a las vinculaciones del código de parentesco con la noción de persona entre los tsotsiles — habitantes de Larráinzar en la descripción de Holland—, que las montañas más altas y alejadas, consideradas sagradas, donde, según se supone, habitan los animales compañeros, son denominadas "ch'iebal”. Este término es cognado del yucateco "ch'ibal”, que es el nombre para el linaje paterno de un individuo. De manera que el wayjel, animal compañero, corresponde al ámbito espacial de las montañas sagradas y al dominio social y simbólico de la filiación que toma la rama paterna.

Al estudiar las representaciones de la naturaleza humana entre los tsotsiles de San Pedro Chenalhó, Calixta Guiteras apunta lo siguiente: 
Mis problemas más arduos eran los relacionados con el concepto del alma [...] La confusión relativa al alma se debía en gran parte a que yo empleaba la palabra castellana alma, que en tsotsil se traduce por ch'ulel, vocablo que indica el alma indestructible. Cuando Manuel me contestaba, empleaba a veces una de ellas y en ocasiones la otra; por tal razón, los conceptos de ch'ulel y wayjel hubieron de discutirse muchas veces antes de que yo pudiera entenderlos, aunque nunca con la claridad que me habría gustado (1996: 13).

Observamos que el problema planteado por esta investigadora no es otro que el de la adecuada traducción de uno o más términos. La idea de que en términos semánticos estrictos no existirían los sinónimos parece ser guía útil en los casos en que se presentan estas dificultades de traducción. Dicho de otro modo, la necesidad de eliminar la ambigüedad en el significado de los términos nos orienta, más allá de la aparente confusión de los conceptos en el discurso de los informantes, hacia la búsqueda de contrastes significativos de naturaleza intercultural.

El estudio del vocabulario yucateco colonial no permite determinar si en tiempos pasados existió entre los mayas yucatecos la idea de un animal compañero como parte constituyente de la caracterización cultural de la persona común. El término "uaay", del yucateco colonial, hace referencia a un conjunto muy amplio de conceptos relacionados con el ámbito del llamado nahualismo. Es seguramente un cognado del tsotsil wayjel. La información que ofrecen las fuentes coloniales sobre esta noción es bastante escasa. En el Calepino de Motul, uaay aparece con el significado de "familiar", una entidad anímica de 
índole animal que es atributo de brujos y hechiceros mayas. De acuerdo con esta fuente, los brujos son capaces de transfigurarse, adoptando figura animal, en virtud de un pacto con el demonio. El uaay, como doble animal del brujo, tiene existencia separada, pero al mismo tiempo lo que acontece al animal le ocurre también a su compañero humano. Se trata de “dos que son uno".

Uaay. Familiar que tienen los nigrománticos, brujos o hechiceros que es algún animal, que por pacto que hacen con el demonio se convierten fantásticamente; y el mal que sucede a tal animal, sucede también al brujo cuyo familiar es.

Yan uaay ch'amac Tiene por familiar a una zorra

Calepino de Motul

La fuentes que hemos consultado no permiten saber con total claridad si la posesión de un uaay o familiar era también propia de las personas comunes, es decir, todos aquellos que no eran brujos. Sin embargo, Álvarez afirma, refiriéndose al maya colonial, que:

...el uay "espíritu" es personal y general, puesto que todos tienen uno y nadie puede existir sin él. Las personas que tienen su uay fuerte y elevado pueden desarrollar una función más, la de transfigurarse en el animal que es su uay o en algún otro animal. Función que por ser altamente especializada era menos frecuente, ya que dependía de una capacidad innata que no todos los individuos poseían, más los estudios y entrenamientos especializados que debían recibirse para poder realizar esa transfiguración. Facultad y conocimiento que generalmente poseían los sacerdotes. Esta segunda función del uay es semejante al nahualismo de la cultura mexica del altiplano de México (1997: 34). 
De acuerdo con esto, la creencia en un uaay individual, como característica de cualquier persona, pudo haber existido entre los mayas de época prehispánica y colonial. Si se admite la identificación del uaay con un tótem personal sugerida por Holland (1989), se observa, pues, que, a diferencia de los especialistas rituales, los individuos con un familiar débil se consideraban carentes de la facultad de transfigurarse en dicho animal totémico.

Por otra parte, el término uaay es homófono de uay-ak, cuyo significado es "sueño", en el sentido de las imágenes y visiones oníricas, como en la acepción siguiente:

nayak pronóstico o palabras de adivinos o de sueños

El término tsotsil "wayjel” también se relaciona con los sueños. Según Guiteras:

La palabra "wayjel" tiene las mismas raíces que los verbos dormir y soñar, que constituyen una misma cosa. Todos los pedranos declaran que las experiencias oníricas se relacionan con el wayjel, e interpretan los sueños de acuerdo con esta creencia. Por lo tanto, la comunicación con las deidades y los muertos, que ocurre en sueños, se efectúa por medio del wayjel (1996: 233).

El Diccionario Maya (Barrera Vásquez 1995) ofrece algunas entradas en las que way se asocia a las nociones de sueño, soñar, visiones, hechizar, y a la capacidad de transformarse por "encantamiento". El Calepino de Motul consigna varios derivados de uaay con el significado de "señal, rastro o figura representativa". Todos ellos se refieren a dobles, 
simulacros, o equivalentes simbólicos. Otras entradas relativas a uaay se relacionan con veneno o ponzoña, como uaayaan, cosa emponzoñada, infectada o dañada. Podemos conjeturar que esta acepción se vincula con el significado de hechizo o embrujo, dando cuenta del efecto contaminante o nocivo del veneno como derivado de la acción mágica del hechicero. La expresión uayab haab hace alusión a los cinco días complementarios del calendario maya, conocidos también como días uayeb, que eran considerados infaustos dentro de la tradición calendárica de los mayas antiguos. Resulta plausible la suposición de que hayan sido llamados de este modo por el hecho de que, en la estructura calendárica, estos días, por así llamarlos "sobrantes" de la cuenta de trece uinales, hayan sido considerados como días fantasmas o como simulacros, necesarios para el mantenimiento lógico de dicha estructura. Parece posible establecer una relación de concomitancia entre este periodo de tiempo infausto y el universo de los dobles, los sueños, los hechizos y la contaminación mágica.

En la concepción de los mayas yucatecos actuales la noción de waay parece no formar parte de la constitución de las personas comunes. Antes bien, se considera waay como un aspecto nocturno y amenazante del mundo sobrenatural, que se presenta en las creencias y narraciones populares bajo la figura de una persona capaz de convertirse en animal, característicamente con la imagen de animales de corral o domésticos. En las poblaciones rurales del Yucatán actual es muy difundida la creencia en el waay chivo o chivo brujo: 
[...] el huay chivo es una persona de carne y hueso que por pactos con el kisín [diablo] se transforma en chivo, sobre todo en las noches lluviosas o frías. Su finalidad es espantar a toda persona o animal doméstico que se le cruza en su camino.

Cuando surge el comentario de que el huay chivo ronda la comunidad, se generan actos de psicosis colectiva. Todos dicen que por la noche le vieron pasar; que en los patios de sus casas escucharon ruidos extraños; comentan las malévolas hazañas de esta bestia diciendo que atacó a alguien por el cabo del pueblo [...]

Según versión popular, la transformación de la persona en animal se realiza dando nueve volantines a la derecha y otros nueve a la izquierda, al mismo tiempo que pronuncia en lengua maya palabras mágico religiosas que solo conocen los iniciados en estos menesteres (Orilla 2002: 22).

También se piensa que los brujos pueden adoptar diversas formas, además del waay chivo, como de waay koot, brujo águila bermeja; waay toro, brujo toro; waay peek, brujo perro; waay mis, brujo gato, y otros: Los brujos adoptan la forma de gallina con pollitos, lechonas con sus crías, mono, xoch, etcétera (ibid).

Como puede apreciarse, waay se asocia con al menos tres acepciones distintas. Por una parte, con la noción de compañero animal, del cual estarían dotadas todas las personas; por otra en tanto familiar de individuos poderosos como los brujos, está asociado con el nahualismo, entendido como la capacidad de transfiguración de algunos individuos humanos en animales. Una última considera las concepciones de los mayas yucatecos 
contemporáneos, donde la noción de waay se concibe como completamente ajena y externa a los individuos o personas normales. Vale la pena observar, además, que en este caso el waay está casi siempre relacionado con animales domésticos, en contraste con los animales salvajes de la concepción tsotsil. Asimismo la figura del waay chivo, y otras del mismo tipo, son generadoras de temor colectivo: “A los niños que acostumbran a dormirse tarde o que salen a jugar hasta muy entrada la noche, sus padres les asustan con la posible presencia del chivo-brujo. Es, pues, este misterioso ente "el coco" de los mayas" (ibid: 23).

\section{CONCLUSIONES}

A través del análisis del significado cultural de algunos lexemas como ool, ánimo; pixan, alma, y uaay, familiar, y su cotejo con otros del tsotsil como ch'ulel, espíritu, y wayjel, compañero animal, podemos hacer algunas inferencias acerca de las nociones de persona en estos dos grupos mayas:

$\checkmark \quad$ La noción de persona entre los mayas yucatecos es una representación centrada en un núcleo o meollo, ool, que está asociado con el corazón y el interior del cuerpo. Se trata de un núcleo irradiador de vida y de las fuerzas expansivas del crecimiento, de la sede principal de los sentimientos y los estados emotivos, y de la voluntad, las intenciones y los deseos humanos. Este centro o meollo de la persona parece revestir connotaciones cosmológicas, en el sentido de que el centro del mundo es asimismo una suerte de corazón. De acuerdo con los datos de que disponemos, resulta llamativa la ausencia de referencias a otros órganos internos del 
cuerpo como el hígado, tan frecuentemente utilizado para simbolizar entidades de tipo anímico y estados emocionales en otras tradiciones culturales, por ejemplo entre los antiguos nahuas.

$\checkmark \quad$ La noción de persona, en la concepción tsotsil y quizá entre los antiguos mayas, está asociada con el desdoblamiento de la personalidad en dos entidades individuales que comparten una misma esencia espiritual, pero que están separadas por un hiato o espacio intermediario cuyas dimensiones coinciden con el perímetro del mundo natural y social más inmediato, en el que se desenvuelve la existencia personal. De manera que la persona parece estar doblemente localizada y distribuida entre puntos muy distantes en el esquema del mundo tsotsil, con un polo en el ámbito humano de la aldea y otro, distante, en el universo animal y natural exterior a los poblados. 


\section{BIBLIOGRAFÍA}

Arzápalo Marín, Ramón, 1995, Calepino de Motul. Diccionario Maya-Español. UNAM, México.

Álvarez, Cristina, 1997, Diccionario Etnolingüístico del Idioma Maya Yucateco Colonial. UNAM, México.

Barrera Vásquez, Alfredo, 1995, Diccionario Maya. Maya-Español, Español-Maya. Porrúa, México.

Bourdin, Gabriel, 2007, El cuerpo humano entre los mayas. Una aproximación lingüística. Universidad Autónoma de Yucatán, Mérida, Yucatán.

Eccles, John , 2000, "El misterio de la psique humana". En El espíritu de la ciencia, editado por David Lorimer, pp. 276-296. Kairós, Barcelona.

Enfield, Nick y Anna Wierzbicka (editores) 2002, The body in description of emotion: cross-linguistic studies. Pragmatics and Cognition, special issue. John Benjamins, Amsterdam-Philadelphia.

García, Hernán, Antonio Sierra y Gilberto Balám, 1996, Medicina maya tradicional. Confrontación con el sistema conceptual chino. Educe, México.

Goddard, Cliff y Anna Wierzbicka (editores), 1994, Semantic and lexical universals. Theory and empirical findings. John Benjamins, Amsterdam-Philadelphia.

Guiteras Holmes, Calixta, [1961] 1996, Los peligros del alma. Visión del mundo de un tzotzil. Primera reimpresión. FCE, México. 
Heelas, Paul, 1996, “Emotion talk across cultures”. En The emotions. Social, cultural and biological dimensions, editado por Harré, Rom y W. Gerrod Parrott, pp. 171-199. Sage Publications, London-Thousand Oaks-New Delhi.

Holland, William, [1962] 1989, Medicina maya en Los Altos de Chiapas. Un estudio del cambio sociocultural. CONACULTA-INI, México.

Kitayama, Shinobu y Hazel R. Markus, 1991, "Culture and the Self: Implications for Cognition, Emotion, and Motivation”. Psychological Review, núm. 98, pp. 224-253. 1994, Emotion and Culture: Empirical studies of mutual influence. American Psychological Association, Washington.

López Austin, Alfredo, 1996, Cuerpo humano e ideología. Las concepciones de los antiguos nahuas. 1ra. reimpresión. UNAM, México.

Martín Morillas, J. M. y J. C. Pérez Rull, 1998, Semántica cognitiva intercultural. Granada Linguiística y Método, Granada, España.

Mauss, Marcel, 1938, “Une catégorie de l'esprit humain: la notion de personne, celle de "moi". Journal of the Royal Anthropological Institute, núm 68, pp. 263-281, London.

Orilla, Miguel A., 2002, Cosas del Mayab. Instituto de Cultura de Yucatán, Mérida.

Schumann, Otto, 1997, Introducción al Maya Mopán. UNAM, México.

Wierzbicka, Anna, 1997, Understanding cultures through their key words: English, Russian, Polish, German, Japanese. Oxford University Press, New York. 
1999, Emotions Across Languages and Cultures: Diversity and Universals. Oxford University Press, Oxford.

\section{ANEXO \\ SÍMBOLOS ALFABÉTICOS UTILIZADOS}

En este artículo se utiliza básicamente el alfabeto empleado para la escritura del maya yucateco colonial, según la edición de Arzápalo (1995) del Calepino de Motul. En los casos donde se transcriben términos en otras lenguas — tsotsil o maya actual— se adopta la grafía de los autores que se citan.

\section{ABREVIATURAS EMPLEADAS EN LA GLOSA INTERLINEAR}
ABS absolutivo
1 primera persona
3 tercera persona
P plural
PREP preposición
POS posesivo
S singular 